Dept. of Zoonoses.,

Faculty of Veterinary Medicine, Benha University.

\title{
PUBLIC HEALTH IMPORTANCE OF ANTIMICROBIAL RESISTANT ESCHERICHIA COLI STRAIN 0157: H7 IN KALYOBIA PROVINCE ABATTOIRS
}

(With 5 Tables)

By

\section{A.A. EL-NEWISHY and SYLVIA O. AHMED*}

* Dept. of Animal Hyg. and Zoonoses, Faculty of Veterinary Medicine, Assiut University.

(Received at 21/3/2011)

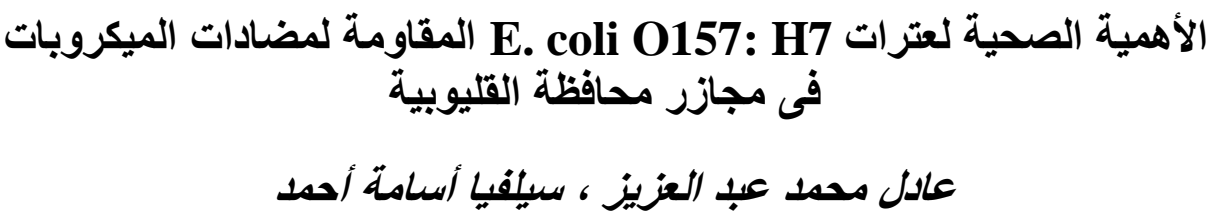

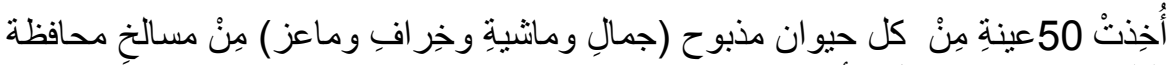
Escherichia coli enterohaemorragic O157: H7 القليوبيةِ ، كانت معدل الأصابة

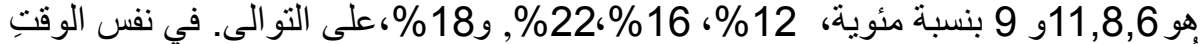

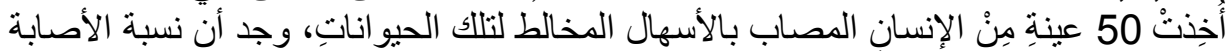
Escherichia coli enterohaemorragic O157: H7

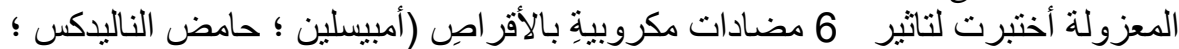

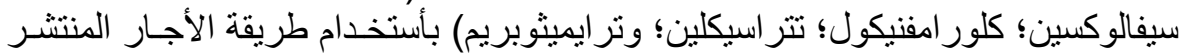

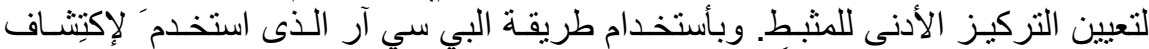

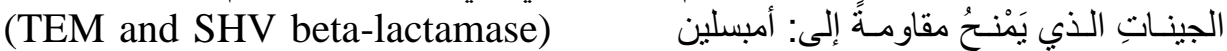

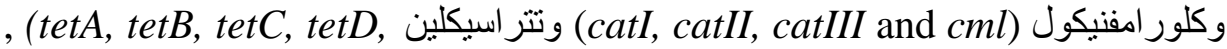
(dfrA1, dfrA9, dfrA12, dfrA13, ترايميثوبريم (tet E and tet $G)$ $. d f r 7$, and $d f r 17)$

\section{SUMMARY}

Out of 50 samples were taken from each carcass of camel, cattle, sheep and goat from Kalyobia province abattoirs, the incidence rates of enterohaemorragic Escherichia coli O157: H7 strain were 6, 8, 11 and 9 with the percentage of $12 \%, 16 \%, 22 \%$ and $18 \%$ respectively. In the same time out of 50 samples were taken from diarrheic human in the 
same localities of animals, the incidence rate of enterohaemorragic Escherichia coli O157: H7 strain was 22 with the percentage of $44 \%$. Isolates were tested for susceptibility to 6 antimicrobial drugs by discs (AMP, ampicillin; NAL, nalidixic acid; CIP, ciprofloxacin; CHL, chloramphenicol; TET, tetracyclin; TRI, trimethoprim) diffusion and agar dilution methods in order to determine minimum inhibitory concentrations (MIC). Multiplex PCR amplification was used to detect genes conferring resistance to: ampicillin (TEM and SHV betalactamase), chloramphenicol (catI, catII, catIII and $\mathrm{cml}$ ), tetracycline (tetA, tetB, tet $C$, tetD, tet $E$ and tet $G$ ), and trimethoprim (dfrAl, dfrA9, $d f r A 12, d f r A 13, d f r 7$, and $d f r 17)$.

Key words: E.coli O157: H7, PCR.

\section{INTRODUCTION}

Bacterial resistance to antimicrobials is a global problem, and understanding the molecular basis of resistance acquisition and transmission can contribute to the development of new strategies to combat this phenomenon. Furthermore, a zoonotic component to bacterial antimicrobial resistance has been demonstrated (Kadlec and Schwarz, 2008). Healthy cattle, camel, sheep and goat are the main recognized animal's reservoir and may harbor Escherichia coli as part of the bowel flora. Most reported outbreaks are due to contaminate food or water, however, direct transmission of E. coli $\mathrm{O} 157$ : $\mathrm{H} 7$ from animals and their environment to humans is a growing concern (Angelo et al., 2004; Nunnery et al., 2006). Escherichia coli O157:H7 is important cause of gastrointestinal illness and are often found in production animal's settings. Escherichia coli O157:H7 can be carried and shed by cattle, camel, sheep and goat, and can be transmitted to humans through drinking of contaminated water and/or consumption of contaminated food of animal origins. Commensal E. coli strains from humans and animals have been reported to express high resistance to common antimicrobial agents, harboring antibiotic resistance genes such as dfrA17 and dfrA12 (Kang et al., 2005; Scott Weese, 2008). These resistance genes are commonly present on mobile genetic elements such as plasmids and integrons in clinical isolates of Gram-negative microorganisms (Alekshun and Levy, 2007). Furthermore, resistance genes selected present in non-pathogenic bacteria may later transfer the acquired resistance to pathogenic bacterial species (Phillips et al., 2004; 
Wassenaar, 2005). Thus, normal bacterial flora can play a key role as an acceptor and donor of antimicrobial resistance (Saenz et al., 2004).

The current study was carried out to throw light on the followings:

1- Incidence of strain Escherichia coli O157: H7 on carcasses of slaughtered animals in Kalyobia province abattoirs.

2- The percentage of strain Escherichia coli O157: H7 isolated from diarrheic human in the same localities of the examined animals.

3- Investigation for antibiotic resistance, resistance genes and their ability to perform horizontal transfer.

\section{MATERIALS and METHODS}

Shortly after the identification of the incriminated pathogen, swabs were taken from surfaces of carcasses of camel, cattle, sheep and goat from Kalyobia province abattoirs, and human in the same localities (Sheila et al., 1967). Sterile cotton tipped swab was immersed in sterile phosphate buffer saline then swabbed over the detectable definitive area and put in a tube containing $10 \mathrm{~cm}$ of phosphate buffer saline which finally represented each carcass (original dilution). The swabs were transferred as rapidly as possible to the laboratory in an ice box (Barraued et al., 1967; Sheila et al., 1967).

Identification of the isolated E. coli: Cultures of the animals and human samples were cultured onto Mac Conkey broth ICMSF,(oxiod), by using Mac Conkey agar medium (oxoid), (code CM7) (Barraued et al., 1967).

Biochemical identification of E.coli isolates was made on the basis of the following tests oxidase test, sugar fermentation and motility test, detection of $\mathrm{H} 2 \mathrm{~S}$, indol production ,methyl red test, voges proskauer test, citrate utilization test, nitrate reduction test, catalase test, lysine decarboxylase test, ornithin decarboxylation and argentine dihydrolase test, urease test, gelatin liquefaction and Eijkhuman test (Baron and Fingold, 1990).

\section{Serotyping of isolates:}

Agglutination tests: After over night incubation, both the confluent growth and selected colonies from plain agar were examined at first trypofluine hydrochloride $(0.2 \%)$ which used to detect rough colonies. Smooth colonies were distinguished on the bases of two classes of antigens, O (somatic) and K (surface) (Edwards and Ewing, 1972; Towner et al., 1994). Results were recorded in Tables (2 \&3). E.coli 
strains that were non -sorbitol fermenting when cultured onto sorbitolMacconkey agar plates were subjected to agglutination test using E.coli O157: H7 antisera (Kimata, 2005).

\section{Antimicrobial sensitivity test:}

Isolates were subjected to antibiotic disc diffusion testing according to the British Society for Antimicrobial Chemotherapy (BSAC) guidelines. Isolates were tested for resistance to the following antibiotics: ampicillin $(30 \mu \mathrm{g})$, chloramphenicol $(30 \mu \mathrm{g})$, nalidixic acid $(30 \mu \mathrm{g})$, ciprofloxacin $(1 \mu \mathrm{g})$, tetracycline $(30 \mu \mathrm{g})$, and trimethoprim $(2.5 \mu \mathrm{g})$. Stringent criteria were adopted for defining multidrug resistance (MDR), including resistance to at least four classes of antimicrobial agents. The MICs of resistant E. coli isolates were determined for each of the following antibiotics: ampicillin, chloramphenicol, ciprofloxacin, tetracycline and trimethoprim using the agar dilution method as described previously, and evaluated according to BSAC guidelines (Jansson et al., 1992).

\section{Identification of antibiotic resistance genes:}

Multiplex PCR amplification was used to identify genes responsible for resistance to: ampicillin, chloramphenicol, trimethoprim and tetracycline. Primer sets for PCR were selected using MacVector ${ }^{\mathrm{TM}}$ 5.0 Sequence Analysis Software (Microbiology Department Benha University Faculty of Medicine, Egypt).

In total, 6 different PCR protocols were applied and Six PCR protocols were applied to detect specific genes according to the resistance phenotype, as follows: TEM and SHV $\beta$-lactamase genes for isolates exhibiting ampicillin resistance (Kimata et al., 2005; Pitout et al., 1998); catI, catII, catIII, (Vassort-Bruneau et al., 1996) and cmlA (Keyes et al., 2000) for chloramphenicol resistance; tetA, tetB, tetC, tetD, tetE and tetG for six genes responsible for tetracycline resistance (Ng LK et al., 2001); dfrA1, dfrA9 (Gibreel and Skold, 1998) and dfrA12, dfrA13, dfrA7, dfrA17 for trimethoprim resistance genes. PCR products of dfrA 7 and dfrA17, dfrA12 and dfrA13 were cleaved using $20 \mathrm{U}$ EcoRV and pst1 (Sigma) respectively. Positive controls were laboratory strains 7071 (dfr12) and 7082a (dfr17). Positive controls for the other resistance genes were DNA samples from bacterial isolates previously characterized and sequenced. 
Table 1: Lists all primer pairs used for Multiplex PCR protocols:

\begin{tabular}{|c|c|}
\hline Primers sequences 5' to $3^{\prime}$ & amplicon size (bp) \\
\hline $\begin{array}{l}\text { Shv: CACTCAAGGATGTATTGTG, } \\
\text { TTAGCGTTGCCAGTGC }\end{array}$ & 885 \\
\hline $\begin{array}{l}\text { Tem: } \text { TCGGGGAAATGTGCGCG, } \\
\text { TGCTTAATCGTGAGGCACC }\end{array}$ & 971 \\
\hline $\begin{array}{l}\text { CatI: AGTTGCTCAATGTACCTATAACC, } \\
\text { TTGTAATTCATTAAGCATTCTGCC }\end{array}$ & 585 \\
\hline $\begin{array}{l}\text { CatII: ACACTTTGCCCTTTATCGTC, } \\
\text { TGAAAGCCATCACATACTGC }\end{array}$ & 495 \\
\hline $\begin{array}{l}\text { CatIII: TTCGCCGTGAGCATTTTG, } \\
\text { TCGGATGAGTATGGGCAAC }\end{array}$ & 508 \\
\hline $\begin{array}{l}\text { cmlA: CCGCCACGGTGTTGTTGTTATC, } \\
\text { CACCTTGCCTGCCCATCATTAG }\end{array}$ & 698 \\
\hline $\begin{array}{l}\text { tet } \mathbf{B}: \text { TTGGTTAGGGGCAAGTTTTG, } \\
\text { GTAATGGGCCAATAACACCG }\end{array}$ & 659 \\
\hline $\begin{array}{l}\text { tet } \mathbf{C}: \text { CTTGAGAGCCTTCAACCCAG, } \\
\text { ATGGTCCTCATCTACCTGCC }\end{array}$ & 418 \\
\hline $\begin{array}{l}\text { tetD: AAACCATTACGGCATTCTGC, } \\
\text { GACCGGATACACCATCCATC }\end{array}$ & 787 \\
\hline $\begin{array}{l}\text { tetA: GCTACATCCTGCTTGCCTTC, } \\
\text { CATAGATCGCCGTGAAGAGG }\end{array}$ & 210 \\
\hline $\begin{array}{l}\text { tetE: AAACCACATCCTCCATACGC, } \\
\text { AAATAGGCCACAACCGTCAG }\end{array}$ & 278 \\
\hline $\begin{array}{l}\text { tetG: GCTCGGTGGTATCTCTGCTC, } \\
\text { AGCAACAGAATCGGGAACAC }\end{array}$ & 210 \\
\hline $\begin{array}{l}\text { dfrl: ACGGATCCTGGCTGTTGGTTGGACGC, } \\
\text { CGGAATTCACCTTCCGGCTCGATGTC }\end{array}$ & 254 \\
\hline $\begin{array}{l}d f r 9: \text { ATGAATTCCCGTGGCATGAACCAGAAGAT, } \\
\text { ATGGATCCTTCAGTAATGGTCGGGACCTC }\end{array}$ & 399 \\
\hline $\begin{array}{l}\text { dfrA7, dfrA17: GTCGCCCTAAAACAAAGTTA, } \\
\text { CGCCCATAGAGTCAAATGT }\end{array}$ & 195 \\
\hline $\begin{array}{l}\text { dfr12, dfrl3: CCGTGGGTCGATGTTTGATG, } \\
\text { GCATTGGGAAGAAGGCGTTCAC }\end{array}$ & 485 \\
\hline
\end{tabular}

Primer sequences and amplification protocols were taken from the following sources: TEM \& SHV $\beta$-lactamase genes (Pitout et al., 1998); catI, catII, catIII (Vassort-Bruneau et al., 1996); cmlA (Keyes et al., 2000); tetA, tetB, tetC, tetD, tetE and tetG (Ng LK et al., 2001); dfrA1, dfrA9 (Gibreel and Skold ,1998); dfrA12, dfrA13, dfrA7, dfrA17 (Lee et al., 2001). 


\section{RESULTS}

Table 2: The percentage of strain O157: $\mathrm{H} 7$ on carcasses of animals in Kalyobia province abattoirs.

\begin{tabular}{|c|c|c|c|c|c|c|c|c|}
\hline \multirow{2}{*}{} & \multicolumn{2}{|c|}{ Camel } & \multicolumn{2}{c|}{ Cattle } & \multicolumn{2}{c|}{ Sheep } & \multicolumn{2}{c|}{ Goat } \\
\cline { 2 - 9 } & $\begin{array}{c}\text { No. } \\
(50)\end{array}$ & $\%$ & $\begin{array}{c}\text { No. } \\
(50)\end{array}$ & $\%$ & $\begin{array}{c}\text { No. } \\
(50)\end{array}$ & $\%$ & $\begin{array}{c}\text { No. } \\
(50)\end{array}$ & $\%$ \\
\hline O157:H7 & 6 & 12 & 8 & 16 & 11 & 22 & 9 & 18 \\
\hline
\end{tabular}

Table 3: The percentage of strain O157: H7 isolated from diseased human in the same locality of animals.

\begin{tabular}{|c|c|c|}
\hline Total No. of samples & $\begin{array}{c}\text { No.of individuals positive } \\
\text { to } \text { E.coli }\end{array}$ & $\begin{array}{c}\% \text { of individual } \\
\text { case isolated }\end{array}$ \\
\hline 50 & 22 & $44 \%$ \\
\hline
\end{tabular}

Table 4: Resistance profiles in strain O157: H7 isolated from animals and human.

\begin{tabular}{|c|c|c|c|}
\hline Abs & $\begin{array}{c}\text { No. of samples with at } \\
\text { least one resistant } \\
\boldsymbol{E} . \boldsymbol{c o l i} \text {; disc diffusion } \\
\text { method in animals }(\%)\end{array}$ & $\begin{array}{c}\text { No. of samples } \\
\text { with at least one } \\
\text { resistant } \boldsymbol{E} . \text { coli; } \\
\text { disc diffusion } \\
\text { method in human } \\
(\%)\end{array}$ & $\begin{array}{c}\text { Total no. of resistant } \\
\boldsymbol{E} \text {. coli; for each disc } \\
\text { diffusion method in } \\
\text { animals and human } \\
(\%)\end{array}$ \\
\hline AMP & $28(\%)$ & $10(\%)$ & $38(\%)$ \\
\hline NAL & $11(\%)$ & $2(\%)$ & $13(\%)$ \\
\hline CIP & $20(\%)$ & $4(\%)$ & $24(\%)$ \\
\hline CHL & $24(\%)$ & $13(\%)$ & $37(\%)$ \\
\hline TET & $22(\%)$ & $17(\%)$ & $39(\%)$ \\
\hline TRI & $31(\%)$ & $20(\%)$ & $51(\%)$ \\
\hline
\end{tabular}

Abbreviation: ABs, antimicrobials; AMP, ampicillin; NAL, nalidixic acid; CIP, ciprofloxacin; CHL, chloramphenicol; TET, tetracyclin; TRI, trimethoprim 
Table 5: Summary of results showing the identification and distribution of antibiotic resistance genes in strain O157: $\mathrm{H} 7$ isolates from animals and human.

\begin{tabular}{|c|c|c|c|c|}
\hline $\begin{array}{c}\text { Antibiotic(No. } \\
\text { of resistant } \\
\text { isolates } \\
\text { investigated) }\end{array}$ & $\begin{array}{l}\text { Source and } \\
\text { number }(N) \text { of } \\
\text { isolates }\end{array}$ & $\begin{array}{c}\text { Identified } \\
\text { by PCR }\end{array}$ & $\begin{array}{c}\text { Not identified } \\
\text { by } \\
\text { PCR }\end{array}$ & $\begin{array}{c}\text { Antibiotic } \\
\text { resistance gene } \\
\text { composition tested } \\
\text { by PCR }\end{array}$ \\
\hline AMP (38) & $\begin{array}{l}\text { Animals } \mathrm{n}= \\
28 \\
\text { human } \mathrm{n}=10\end{array}$ & $\begin{array}{c}22 \\
7\end{array}$ & $\begin{array}{l}6 \\
3\end{array}$ & $\begin{array}{l}\text { TEM \& SHV } \beta \text { - } \\
\text { lactamase genes }\end{array}$ \\
\hline CHL (37) & $\begin{array}{l}\text { Animals } n= \\
24 \\
\text { human } n=13\end{array}$ & $\begin{array}{c}16 \\
9\end{array}$ & $\begin{array}{l}8 \\
4\end{array}$ & $\begin{array}{c}\text { catI catII catIII } \\
\text { cmlA }\end{array}$ \\
\hline TET (39) & $\begin{array}{l}\text { Animals } \mathrm{n}= \\
22 \\
\text { human } \mathrm{n}=17\end{array}$ & $\begin{array}{l}19 \\
14\end{array}$ & $\begin{array}{l}3 \\
3\end{array}$ & $\begin{array}{c}\text { tetB tet } A \text { tet } C \text { tetD } \\
\text { tetE tet } G\end{array}$ \\
\hline TRI (51) & $\begin{array}{l}\text { Animals } n= \\
31 \\
\text { human } n=20\end{array}$ & $\begin{array}{l}27 \\
17\end{array}$ & $\begin{array}{l}4 \\
3\end{array}$ & $\begin{array}{l}\text { dfrA1 dfrA17 } \\
\text { dfrA12 dfrA9 } \\
d f r A 7, d f r A 13\end{array}$ \\
\hline
\end{tabular}

All genes listed were tested by PCR amplification using gene-specific primer pairs listed in Table 1. Genes positively identified by PCR are shown in bold, and are listed according to their frequency of occurrence within each resistance group.

Abbreviations: AMP, ampicillin; CHL, chloramphenicol; TET, tetracycline; TRI, trimethoprim

\section{DISCUSSION}

In this study we isolated and identified Escherichia coli $\mathrm{O} 157: \mathrm{H} 7$ serotypes from some animals carcasses and diarrheic human in the same localities at Kalyobia province, the samples were taken from carcasses of camel; cattle, sheep and goat at Kalyobia province abattoirs, in the same manner human samples were taken from individual case occupational contact with these animals. Escherichia coli isolated were investigated for antibiotic resistance, resistance genes and their ability to perform horizontal transfer.

Table 2 recorded that the incidence rate of enterohaemorragic Escherichia coli strain O157:H7 on the surface of the carcasses of camel, cattle, sheep and goat at Kalyobia province abattoirs was 2, 8, 11 and 9 with the percentage of $12 \%, 16 \%, 22 \%$ and $18 \%$ respectively. The incidences recorded were agreed with Warburton and Todd (1995) who stated that Escherichia coli O157: H7 bacterium is believed to mostly live in the intestines of cattle and sheep. E. coli O157: H7 does not make 
the animals that carry it ill; the animals are merely the reservoir for the bacteria.

Meat typically becomes contaminated with E. coli O157: H7 during the slaughtering process, when the intestinal contents of the animal are allowed to come into contact with the carcass. Unless the carcass is sanitized somehow, the E. coli bacteria are eventually mixed into the meat. Thorough cooking is required to prevent $E$. coli $\mathrm{O} 157: \mathrm{H} 7$ infection when the meat is eaten by the consumer (Ingham and Schmidit, 2000; Elder and Keen, 2000).

Table 3 recorded that the incidence rate of O157: H7 E.coli strains out of 50 samples taken from the diarrheic human in the same localities of tested animals, 22 cases were positive to that strain with percentage $44 \%$. The high incidence may be explain the wide distribution of E.coli in the examined area and also explain the role of E.coli in case of diarrhea in human and different animal species and denotes the zoonotic problem of colibacillosis in both human and animals is present. The incidences recorded agreed with Mackenzie et al. (1998).

Table 4 show that among samples from the human samples, 20/22 contained at least one antibiotic-resistant E. coli isolate, whereas only $31 / 34$ of the carcasses of camel, cattle, sheep and goat at Kalyobia province abattoirs samples contained resistant isolates. The number of isolates in both animals and human showing resistance to each antimicrobial agent were: trimethorpim $(n=51)$, tetracycline $(n=39)$, ampicillin $(\mathrm{n}=38)$, chloramphenicol $(\mathrm{n}=37)$, nalidixic acid $(\mathrm{n}=13)$, ciprofloxacin $(\mathrm{n}=24)$. The incidences recorded agreed with Angelo et al. (2004).

Table 5 in total, 6 resistance genes were identified Ampicillin resistant isolates, all of which were of animal's origin was attributable to TEM \& SHV $\beta$-lactamase genes in \% (38/56). Of the Chloramphenicol resistant isolates, $66 \%(37 / 56)$ were positive by PCR for cat genes, with catI the most prevalent gene $(61 \%)$, followed by catII at $18 \%$ and catIII at $11 \%$ and $\mathrm{cmlA} 10 \%$. Of the tetracycline resistant isolates, $69 \%$ (39/56) were positive by PCR for tet genes, with tetB the most prevalent gene $(71 \%)$, followed by tetA at $18 \%$ and tet $(\mathrm{A}+\mathrm{B})$ at $11 \%$. Trimethoprim resistant isolates, all of which were of animal's origin was attributable to dfr genes in $91 \%(51 / 56)$ at the following frequencies: dfr1 (40.3\%), dfr17 (28\%), dfr12 (17.3\%) and dfr9 (0.3\%).

Ampicillin resistance in E. coli isolates described in this paper was largely associated with TEM $\beta$-lactamase genes, with only one isolate 
positive for SHV $\beta$-lactamase genes. This agrees with other reports that TEM $\beta$-lactamase genes (i.e. TEM-1 $\beta$-lactamase gene) are the most prevalent in ampicillin resistant $E$. coli of animal origin, as well as being commonly reported in human E. coli isolates (Brinas et al., 2002; Hanberger et al., 2009) with variations between countries. ESBLtargeted drugs are being used more frequently, but may results in mutations of TEM and SHV $\beta$-lactamase genes, as well as the widely prevalent ctx-m types (Paterson and Bonomo, 2005).

In our study, the tetB gene was the most prevalent $(71 \%)$ tetracycline resistance gene, followed by tetA (18\%), and no other tet gene was identified. This prevalence pattern has also been reported in $E$. coli strains from various animals. The tetB gene has the widest host range among gram-negative pathogens (Brinas et al., 2002). There is evidence for a correlation between the widespread distribution of tetracycline resistance genes and the sub-therapeutic antimicrobial use of tetracycline (Paterson and Bonomo, 2005). Suggesting that resistance to chloramphenicol is likely to be part of a multiple resistance system. The use of chloramphenicol in veterinary medicine is generally restricted to topical application as a treatment for ophthalmic conditions, and is hardly ever used systemically. Chloramphenicol resistance was almost exclusively found in hospital-derived samples indicating that, as with tetracycline resistance, chloramphenicol resistance has most probably been co-selected via linked trimethoprim and ampicillin resistance genes.

A large proportion (93\%) of the trimethoprim resistant isolates was positive for at least one of the dfr genes, which are commonly encoded on mobile genetic elements. Particularly, dfrA1 has spread rapidly on the transposon $\operatorname{Tn} 7$ to become the most prevalent gene responsible for trimethoprim resistance (Bryan et al., 2004), and the most prevalent in our study, followed by dfrA12 and dfrA17. The dfrA9 was found only in one isolate in the present study. The dfrA9 gene, first reported in porcine $E$. coli strains, has also been reported in veterinary isolates and spread to human strains probably as a consequence of the extensive use of potentiated sulphonamide products (e.g. trimethoprim) in veterinary medicine (Chopra and Roberts, 2001). Reportedly, dfr genes are mostly conjugally transferable. In studies on $E$. coli isolates of human origin, the wide dissemination of dfrA17 of $E$. coli isolates is mainly due to the horizontal transfer of class 1 integrons, via conjugative plasmids (Stine et al., 2007). Similarly, horizontal transfer through conjugative plasmids has been reported to be responsible for the wide 
dissemination of mobile genetic elements (e.g. class 1 integrons) in E. coli isolates from human and animals (Kang et al., 2005).

The resistant isolates suggests that in occupational animals contact human, antibiotic resistance is conferred by the same E. coli resistance genes found in other animal species. Antibiotic resistance can arise in the absence of selective pressures where antibiotic resistance genes are linked on a mobile genetic element; in these cases, exposure to a single antimicrobial agent has been shown to give rise to co-selection of multiple antibiotic resistance genes. Furthermore, stopping treatment, and consequent removal of selective pressure, does not necessarily lead to the loss of resistance (Singer et al., 2004). Resistance to a range of antimicrobials can thus be selected for by administrating one, or a subset, of antimicrobials. The shedding of resistant bacteria could thus produce a reservoir of resistant bacteria in the environment (Sheila et al., 1967). This type of mechanism may account for the presence of genes conferring resistance to tetracyclines and chloramphenicol, which are very rarely used therapeutically in animal's veterinary medicine. Further work is required to define the multidrug resistant mechanisms, that may be responsible for the high level of prevalence of the resistance profiles (AMP, CHL, TET, TRI, NAL; AMP, CHL, TET, TRI; AMP, TET, TRI, NAL) we have identified. That most of these were from animals sources might explain the possible role of antimicrobials in the dissemination and development of resistance in this environment Thus, animals at abattoirs may be both recipients, and sources of the zoonotic transmission of antibiotic resistance, as well as providing an extensive reservoir for antimicrobial resistance genes.

\section{CONCLUSION}

From this work we conclude that E. coli $\mathrm{O} 157: \mathrm{H} 7$ infections were directly transmitted from animals and their environment to people. Contact with animals and their environment were associated with illness. This suggested a probable animal source of infection this case stresses the necessity of informing susceptible hosts at risk of contracting zoonotic agents about some basic hygiene rules when animals slaughters at abattoirs. The most ecological evidence warns that better control of antibiotics on an international scale is the key factor needed to reduce the emergence of antibiotic-resistant organisms, including their maintenance in carriers. It may be necessary to avoid such practices as prophylactic and broad-spectrum therapy without sensitivity testing, and dissemination of residual antibiotics into the environment of human and 
animals. The frequency of $E$. coli O157: $\mathrm{H} 7$ herds combined with the environmental persistence of the organism supports the recommendations that all animals should be handled as if they are colonized and that all animals environments should be approached as if they were contaminated with E. coli O157: H7. Prevention strategies were developed to help reduce the risk of transmission of enteric pathogens at abattoir. The strategies include the use of hand washing, controlled and supervised contact with animals, and clear separation of food-related activities from areas housing animals. Evidence is growing that contact with farm animals and their environment is a substantial contributor to the risk of E. coli O157: H7 infection. This outbreak underscores the need to consider zoonotic transmission during searches for the source of E. coli O157: $\mathrm{H} 7$ and other enteric infection and that simple measures such as effective among all abattoir visitors, the data showed a trend toward hand washing as providing protection and also can make contact with farm animals and their environments safer. Preventive measures may reduce the number of cattle that carry it and the contamination of meat during slaughter and grinding.

The hygienic instruction of the slaughterhouse should be strictly imposed with daily washing and disinfecting of floor, walls and all other utensils with known powerful bacteriocidal agents. Perfect meat inspection, and the design of abattoir should be appropriate so as to prevent the contamination of sound meat from offal and the diseased parts, maximal possible measures for prevention of the cross contamination should be practiced. All persons engaged in the handling of meat and meat products should be healthy, have medical certificates, and clean since contaminated hands may pass infection to food, the food handlers must be provided with suitable protective clothing, sterile gloves for handling meat and meat products in order to obtain meat with possible no bacterial pathogens.

The genes we have identified as responsible for antibiotic resistance in animals food $E$. coli are commonly found in other domestic animals and human. Antibiotic resistance found in animals carcasses probably originates from, and is selected by the same sources and mechanisms as in other animal species. Thus, in Kalyobia abattoirs animals may be both recipients, and sources of the zoonotic transmission of antibiotic resistance, as well as providing an extensive reservoir for antimicrobial resistance genes. 


\section{REFERENCES}

Alekshun, MN. and Levy, SB. (2007): Molecular mechanisms of antibacterial multidrug resistance. Cell.;128(6):1037-1050.

Angulo, FJ.; Nunnery, JA. and Bair, HD. (2004): Antimicrobial resistance in zoonotic enteric pathogens. Rev. Sci. Tech.; 23(2): 485-496.

Baron, E.J. and Fingold, S.M. (1990): Diagnostic Microbiology. The C.V.Mosby Company. Siant. Lous. Baltimore Philadelphia, Toronto.

Barraued, C.; Kitchell, A.G.; Labots, H.; Reuter, G. and Simmonen, B. (1967): Standardization of total aerobic count in meat and meat products. Fleischwirtschaft:47: 1313-1321.

Brinas, L.; Zarazaga, M.; Saenz, Y.; Ruiz-Larrea, F. and Torres, C. (2002): Beta-lactamases in ampicillin-resistant Escherichia coli isolates from foods, human, and healthy animals. Antimicrob. Agents Chemother.; 46(10): 3156-3163.

Bryan, A.; Shapir, N. and Sadowsky, MJ. (2004): Frequency and distribution of tetracycline resistance genes in genetically diverse, nonselected, and nonclinical Escherichia coli strains isolated from diverse human and animal sources. Appl. Environ. Microbiol. 70(4): 2503-2507.

Chopra, I. and Roberts, M. (2001): Tetracycline antibiotics: mode of action, applications, molecular biology, and epidemiology of bacterial resistance. Microbiol. Mol. Biol. Rev. 65(2):232-260.

Edwards, PR. and Ewing, W.H. (1972): Identification of Enterobacteriaceae 3rd edition Minneaplis: Burgess, Publishing Company.

Elder, R.O. and Keen, J.E. (2000): Correlation of Enterohemorrhagic Escherichia coli $\mathrm{O} 157$ prevalence in feces, hides, and carcasses of beef battle during processing. Proc. Natl. Acad. Sci. USA, 97: 2999-3003.

Gibreel, A. and Skold, O. (1998): High-level resistance to trimethoprim in clinical isolates of Campylobacter jejuni by acquisition of foreign genes (dfr1 and dfr9) expressing drug-insensitive dihydrofolate reductases. Antimicrob. Agents Chemother. 42(12): 3059-3064.

Hanberger, H.; Arhuman, D.; Gill, H.; Jindrak, V.; Kalenic, S.; Kurcz, A.; Licker, M.; Naaber, P.; Scicluna, EA. and Vanis, V. (2009): Surveillance of microbial resistance in European Intensive Care 
Units: a first report from the Care-ICU programme for improved infection control. Intensive Care Med. 35(1):91-100.

Ingham, S.C. and Schmidit, D.J. (2000): Alternative indicator bacteria analysis for evaluation the sanitary condition of beef carcasses. J. Food Protection 63(1): 51-55.

Jansson, C.; Franklin, A and Skold, O. (1992): Spread of a newly found trimethoprim resistance gene, dhfrIX, among porcine isolates and human pathogens. Antimicrob. Agents Chemother. 36(12): 2704-2708.

Kadlec, K. and Schwarz, S. (2008): Analysis and distribution of class 1 and class 2 integrons and associated gene cassettes among Escherichia coli isolates from swine, horses, cats and dogs collected in the BfT-GermVet monitoring study. J. Antimicrob. Chemother. 62(3):469-473.

Kang, HY.; Jeong, YS.; Oh, JY.; Tae, SH.; Choi, CH.; Moon, DC.; Lee, WK.; Lee, YC. Seol, SY. and Cho, DT. (2005): Characterization of antimicrobial resistance and class 1 integrons found in Escherichia coli isolates from human and animals in Korea. J. Antimicrob. Chemother. 55(5):639-644.

Keyes, K.; Hudson, C.; Maurer, JJ.; Thayer, S.; White, DG. and Lee, MD. (2000): Detection of florfenicol resistance genes in Escherichia coli isolated from sick chickens. Antimicrob. Agents Chemother. 44(2): 421-424.

Kimata, K.; Shima, T.; Shimizu, M.; Tanaka, D.; Isobe, J.; Gyobu, Y.; Watahiki, M. and Nagai, Y. (2005): Rapid categorization of pathogenic Escherichia coli by multiplex PCR. Microbiol. Immunol. 49(6): 485-492.

Lee, JC.; Oh, JY.; Cho, JW; Park, JC.; Kim, JM.; Seol, SY. and Cho, DT. (2001): The prevalence of trimethoprim-resistanceconferring dihydrofolate reductase genes in urinary isolates of Escherichia coli in Korea. J. Antimicrob. Chemother. 47(5): 599-604.

Mackenzie, A.M.R.; Lebel, P.; Orrbine, E.; Rowe, P.C.; Hyde, L.; Chan, F.; Johnson, W. and McLaineand, P.N. (1998): The Synsorb Pk. Sensitivities and Specificity's of Premier E. coli O157 and Premier EHEC Enzyme Immunoassays for Diagnosis of Infection with Verotoxin (Shiga-Like Toxin) Producing Escherichia coli. Journal of Clinical Microbiology, 36, (6): 1608-1611. 
Ng, LK.; Martin, I.; Alfa, M. and Mulvey, M. (2001): Multiplex PCR for the detection of tetracycline resistant genes. Mol. Cell. Probes. 15(4): 209-215.

Nunnery, J.; Angulo, FJ. and Tollefson, L. (2006): Public health and policy. Prev. Vet. Med. 73(2-3): 191-195.

Paterson, DL. and Bonomo, RA. (2005): Extended-spectrum betalactamases: a clinical update. Clin. Microbiol. Rev. 18(4): 657-686. doi: 10.1128/CMR.18.4.657-686.

Phillips, I.; Casewell, M.; Cox, T.; De Groot, B.; Friis, C.; Jones, R.; Nightingale, C.; Preston, R. and Waddell, J. (2004): Does the use of antibiotics in food animals pose a risk to human health? A critical review of published data. J. Antimicrob. Chemother. 53(1): 28-52.

Pitout, JD.; Thomson, KS.; Hanson, ND.; Ehrhardt, AF.; Moland, ES. and Sanders, CC. (1998): Beta-Lactamases responsible for resistance to expanded-spectrum cephalosporins in Klebsiella pneumoniae, Escherichia coli, and Proteus mirabilis isolates recovered in South Africa. Antimicrob. Agents Chemother. 42(6): 1350-1354.

Saenz, Y.; Brinas, L.; Dominguez, E.; Ruiz, J.; Zarazaga, M.; Vila, J. and Torres, C. (2004): Mechanisms of resistance in multipleantibiotic-resistant Escherichia coli strains of human, animal, and food origins. Antimicrob. Agents Chemother. 48(10): 3996-4001.

Scott Weese, J. (2008): Antimicrobial resistance in companion animals. Anim. Health Res. Rev. 9(2): 169-176.

Singer, RS.; Patterson, SK.; Meier, AE.; Gibson, JK.; Lee, HL. and Maddox, CW. (2004): Relationship between phenotypic and genotypic florfenicol resistance in Escherichia coli. Antimicrob. Agents Chemother. 48(10): 4047-4049.

Sheila, P.; Richards, I.D.G.; Parker, M.T. and Lidwell, O.M. (1967): Nasal and skin samples from patients undergoing surgical operation. J. Hyg. Comb. 65, 559-566.

Stine, OC.; Johnson, JA.; Keefer-Norris, A.; Perry, KL; Tigno, J.; Qaiyumi, S.; Stine, MS. and Morris, JG Jr. (2007): Widespread distribution of tetracycline resistance genes in a confined animal feeding facility. Int. J. Antimicrob Agents. 29(3): $348-352$. 
Towner, KJ.; Brennan, A.; Zhang, Y.; Holtham, CA.; Brough, JL. and Carter, GI. (1994): Genetic structures associated with spread of the type Ia trimethoprim-resistant dihydrofolate reductase gene amongst Escherichia coli strains isolated in the Nottingham area of the United Kingdom. J. Antimicrob. Chemother. 33(1): 25-32.

Vassort-Bruneau, C.; Lesage-Descauses, MC.; Martel, JL.; Lafont, JP. and Chaslus-Dancla, E. (1996): CAT III chloramphenicol resistance in Pasteurella haemolytica and Pasteurella multocida isolated from calves. J. Antimicrob. Chemother. 38(2): 205-213.

Warburton, D. and Todd, E. (1995): Detection of enterohemorrhagic E. coli (EHEC) in food products and food ingredients by assurance EHEC enzyme immunoassay (EIA) method. In: Laboratory procedures for the microbiological analysis of foods. Vol. 3. Compendium of Analytical Methods. Ottawa.

Wassenaar, TM. (2005): Use of antimicrobial agents in veterinary medicine and implications for human health. Crit. Rev. Microbiol. 31(3): 155-169. 